\title{
Surface only modification of bacterial cellulose nanofibres with organic acids
}

\author{
Koon-Yang Lee ${ }^{1}$, Franck Quero ${ }^{2}$, Jonny J. Blaker ${ }^{1}$, Callum A.S. Hill ${ }^{3}$,
}

Stephen J. Eichhorn ${ }^{2}$ and Alexander Bismarck ${ }^{1}$

\footnotetext{
${ }^{1}$ Polymer and Composite Engineering ( $\mathrm{PaCE}$ ) Group, Department of Chemical Engineering, Imperial College London, South Kensington Campus, London, SW7 2AZ, UK.

${ }^{2}$ Material Sciences Centre, School of Materials and the Northwest Composite Centre, University of Manchester, Grosvenor Street, Manchester, M1 7HS, UK.

${ }^{3}$ Centre for Timber Engineering, Napier University, Merchiston Campus, 10 Colinton Road, Edinburgh, EH10 5DT, UK.
}

\begin{abstract}
Bacterial cellulose $(\mathrm{BC})$ nanofibres were modified only on their surface using an esterification reaction with acetic acid, hexanoic acid or dodecanoic acid. This reaction rendered the extremely hydrophilic surfaces of $\mathrm{BC}$ nanofibres hydrophobic. The hydrophobicity of $\mathrm{BC}$ increased with increasing carbon chain length of the organic acids used for the esterification reaction. Streaming (zeta-) potential measurements showed a slight shift in the isoelectric point and a decrease in $\zeta_{\text {plateau }}$ was also observed after the esterification reactions. This was attributed to the loss of acidic functional groups and increase in hydrophobicity due to esterification of $\mathrm{BC}$ with organic acids. A method based on hydrogen/deuterium exchange was developed to evaluate the availability of surface hydroxyl groups of neat and modified $\mathrm{BC}$. The thermal degradation temperature of modified BC sheets decreased with increasing carbon chain length of the organic acids used. This is thought to be a direct result of the esterification reaction, which significantly reduces the packing efficiency of the nanofibres because of a reduction in the number of effective hydrogen bonds between them.
\end{abstract}

Keywords: Bacterial cellulose; surface modification and characterisation; organic acid esterification; zeta-potential; dynamic vapour sorption

Corresponding author: Tel: +44 (0)20 7594 5578, Fax: +44 (0)20 7594 5638, email address: a.bismarck@imperial.ac.uk 


\section{Introduction}

A research area that has been receiving much attention recently is the modification of cellulose for the development of bio-based materials and composites (Ifuku et al. 2007; Nogi et al. 2006; Suetsugu et al. 2009; Bismarck 2008). Cellulose is a linear macromolecule consisting of a repeat unit comprising two D-anhydroglucose rings linked by $\beta(1 \rightarrow 4)$ glycosidic bonds. It is the most abundant organic homopolymer on earth. Cellulose has found numerous industrial applications; in the pharmaceutical and cosmetic industries (Klemm et al. 2005), paper industry (Sczostak 2009) and more recently in composites for the production of so-called 'green' (nano)composite materials (Gindl and Keckes 2004; Nakagaito et al. 2009; Suryanegara et al. 2009; Mathew et al. 2005; Juntaro et al. 2008; Juntaro et al. 2007; Pommet et al. 2008). Unfortunately, the major challenge of utilising (ligno)cellulosic materials, such as natural fibres, in composite applications is its extremely hydrophilic nature (Gardner et al. 2008), high linear coefficient of thermal expansion (LCTE) (Thomason 2009) and poor transverse properties (Cichocki and Thomason 2002). Due to the high LCTE of natural fibres, the residual stresses exerted on natural fibres by the matrix in a composite will be lowered, leading to low interfacial shear stresses between the fibres and a polymeric matrix, as the interfacial shear stress is the product of residual stress and static coefficient of friction of the fibres. As a result, the compatibility between natural fibres and hydrophobic thermoplastics (such as polypropylene and polylactic acid) is often poor (Pommet et al. 2008; Baltazar-y-Jimenez et al. 2008). To overcome this challenge, nanocellulose can be coated onto the surface of natural fibres (Juntaro et al. 2008; Juntaro et al. 2007; Pommet et al. 2008) (thereby creating "hairy natural fibres") to bridge the gap between the natural fibres and the matrices caused by the high LCTE of natural fibres. However, nanocellulose itself is still hydrophilic in nature and cellulose modification is therefore needed to improve the compatibility between cellulose and hydrophobic (renewable) thermoplastics (Li et al. 2007; Baltazar-y-Jimenez et al. 2008a).

In addition to plant sources, cellulose can also be derived from bacteria, such as from the Acetobacter xylinum species (Iguchi et al. 2000). Bacterial cellulose (BC) is being currently explored for/or used already in biomedical applications (Czaja et al. 2007), the production of high quality papers (Iguchi et al. 2000), diaphragms for electroacoustic 
transducers (Nishi et al. 1990), optically transparent films (Nogi et al. 2006; Ifuku et al. 2007) and nowadays as reinforcements for polymers (Eichhorn et al. 2010). Such extensive use of $\mathrm{BC}$ is due to the fact that the material has the advantage of being free of wax, hemicellulose, lignin and pectin, which are present in most plant based cellulosic materials (Iguchi et al. 2000), with cotton as the exception (Bismarck et al. 2005). In addition to this, $\mathrm{BC}$ is inherently nano-sized; with individual fibres having diameters ranging from 24 to $86 \mathrm{~nm}$ and are several micrometres in length (Chanliaud et al. 2002). This feature differs from plant based natural fibres, which have to be homogenised or fibrillated to obtain nanofibres (microfibrillated or nanofibrillated cellulose) (Nogi et al. 2006). X-ray diffraction (XRD) has also revealed that $\mathrm{BC}$ has a very high degree of crystallinity of about 90\% (Czaja et al. 2004). In terms of its mechanical properties, Hsieh et al. (2008) have determined the Young's modulus of single bacterial cellulose nanofibres using Raman spectroscopy. They found that bacterial cellulose nanofibres possess a Young's modulus of $114 \mathrm{GPa}$, with a theoretical Young's modulus of between 130 to $160 \mathrm{GPa}$ depending on its crystal form (Eichhorn and Davies 2006; Reiling and Brickmann 1995). Moreover, BC also has a very low thermal expansion coefficient of $0.1 \times 10^{-6} \mathrm{~K}^{-1}$ (Nishino et al. 2004). All these properties are highly favourable for using BC as a nanofiller/reinforcement in green nanocomposite materials.

As already mentioned, the hydrophilic nature of cellulose will often result in poor compatibility between cellulose and hydrophobic polymer matrices. This will then lead to poor stress transfer efficiency between the matrix and the reinforcement. In order to utilise the full potential of $\mathrm{BC}$ as nanofiller for composites, a reliable surface-only modification is needed to tailor the surface properties of BC without affecting its bulk properties by turning it, for example into a cellulose ester, such as cellulose acetate. This will mean that the compatibility between $\mathrm{BC}$ and hydrophobic polymer matrices such as polylactides can be improved (Lee et al. 2009). Grafting of polymers (Roy et al. 2009) or adsorptions of surfactants (Samir et al. 2005) onto cellulose surface have been investigated in order to functionalise and compatibilise cellulose with a matrix. However, the process of polymer grafting suffered from a lack of control, which prevents the design of well-defined materials. Moreover, although polymer grafting enhances the interaction with polymers, it limits the use of polymer-graft-BC for matrices consisting either of the 
grafted polymer or polymers the grafted polymer is miscible with, which are limited. On the other hand, in order to fully cover the surface of cellulose with surfactants, large quantities of surfactants are needed, usually 4 times the mass of cellulose (Samir et al. 2005). This results in the increase in the raw material cost.

Heterogeneous esterification of cellulose nanofibres with organic acids usually resulted in significant bulk modification, characterised by loss of crystallinity and high degree of substitutions (Berlioz et al. 2009; Ifuku et al. 2007; Suetsugu et al. 2009). BC has also been esterified homogeneously in ionic liquids to produce cellulose acetate but the crystal structure of modified cellulose once regenerated is destroyed (Schlufter et al. 2006). By restricting the modification only to the surface of $\mathrm{BC}$ nanofibres, the highly crystalline bulk structure of $\mathrm{BC}$ can be retained, while the surface is rendered hydrophobic. In this present work, we focus on the heterogeneous surface esterification of $\mathrm{BC}$ nanofibres with various organic acids, namely acetic, hexanoic and dodecanoic acid. In a recent study (Lee et al. 2009) we did demonstrate significant improvements in thermo-mechanical as well as mechanical properties over the neat poly(L-lactic acid) (PLLA) by using these esterified $\mathrm{BC}$ nanofibres as a reinforcemennt for polylactic acid-based nanocomposites. This current work will investigate and characterise the surface and bulk properties of $\mathrm{BC}$ as a result of organic acids modification.

\section{Experimental}

\subsection{Materials}

Acetic acid (analaR, purity $\geq 99.8 \%$ ), methanol (GPR, purity $\geq 99 \%$ ), ethanol (GPR, purity $\geq 99 \%$ ) and pyridine (analaR NORAMPUR, purity $\geq 99.7 \%$ ) were purchased from VWR. Hexanoic acid (purity $\geq 99.5 \%$ ), dodecanoic acid (purity $\geq 98 \%$ ), and $p$ toluenesulfonyl chloride (purity $\geq 99 \%$ ), dimethyl carbonate (purity $\geq 99 \%$ ) and deuterium oxide (purity $\geq 99.99$ atom\% D) were purchased from Sigma-Aldrich. Sodium hydroxide (purum grade, pellets) was purchased from Acros Organics. All the materials were used without any further purification. Bacterial cellulose was extracted from commercially available Nata-de-coco (CHAOKOH gel in syrup, Ampol Food Processing Ltd, Nakorn Pathom, Thailand). 


\subsection{Extraction and purification of bacterial cellulose}

Bacterial cellulose was extracted from 10 jars of Nata-de-coco.(Juntaro 2009) Firstly, Nata-de-coco was rinsed with de-ionised water $\left(3 \times 10 \mathrm{dm}^{3}\right)$ to wash away the sugar syrup. The washed Nata-de-coco was then blended for 1 min using a laboratory blender (Waring Blender LB20EG, Christison Particle Technologies, Gateshead, UK). This BC blend was then homogenised (Polytron PT 10-35 GT, Kinematica, Lucerne, Switzerland) for $2 \mathrm{~min}$ and centrifuged at 14,000g to remove the excess water. To further purify BC, the centrifuged material was re-dispersed in de-ionised water $\left(10 \mathrm{dm}^{3}\right)$. Sodium hydroxide ( $40 \mathrm{~g}, 1 \mathrm{~mol}$ ) was added into this mixture and heated to $80^{\circ} \mathrm{C}$ for $20 \mathrm{~min}$, whilst stirring to remove any soluble polysaccharides (Toyosaki et al. 1996). The purified $\mathrm{BC}$ was then successively centrifuged and homogenised back to neutral $\mathrm{pH}$ using deionised water $\left(4 \times 10 \mathrm{dm}^{3}\right)$.

\subsection{Surface only modification of bacterial cellulose}

In order to modify the surfaces of $\mathrm{BC}$ nanofibres, the purified material $(2 \mathrm{~g}, 12.3 \mathrm{mmol}$ ) was solvent exchanged from water through methanol $\left(3 \times 600 \mathrm{~cm}^{3}\right)$ into pyridine $(2 \times$ $600 \mathrm{~cm}^{3}$ ). This mixture was then homogenised at 20,000 rpm for at least $1 \mathrm{~min}$ at each stage to completely disperse $\mathrm{BC}$ in the solvent ${ }^{\S}$. $\mathrm{BC}$ was retained through centrifugation at $14,000 \mathrm{~g}$ at each stage before re-dispersing it in the subsequent solvent. Another solvent exchange step was performed to adjust the final concentration of $\mathrm{BC}$ in pyridine to $0.5 \%$ $\left(\mathrm{g} \mathrm{cm}^{-3}\right)$. The BC-pyridine mixture was then poured into a $1 \mathrm{dm}^{3} 3$-neck round bottom flask and stirred using a magnetic stirrer. $p$-Toluenesulfonyl chloride (92 g, $0.48 \mathrm{~mol}$ ) was added into this BC-pyridine mixture and an equimolar amount of organic acid (0.48 mol) was added into the reaction vessel after the addition of $p$-toluenesulfonyl chloride. The reaction was conducted for $2 \mathrm{~h}$ at $50^{\circ} \mathrm{C}$ under nitrogen flow to create an inert atmosphere such that water vapour present in the atmosphere does not affect the esterification reaction. The reaction medium was then quenched with ethanol $\left(1.5 \mathrm{dm}^{3}\right)$.

\footnotetext{
Since we do not know the molecular weight of $\mathrm{BC}$, this value was obtained by using the molecular weight of the glucose-repeating unit in cellulose $\left(\mathrm{C}_{6} \mathrm{H}_{10} \mathrm{O}_{5}\right)$.

$\S$ Although starting the reaction with freeze-dried BC is possible, which allows for the re-dispersion of $\mathrm{BC}$ in the reaction medium, its modification results in significant bulk modification of $\mathrm{BC}$ for which we have no explanation to date.
} 
The modified $\mathrm{BC}$ was then washed with ethanol again $\left(3 \times 800 \mathrm{~cm}^{3}\right)$ using the previously described homogenisation-centrifugation step. The product was solvent exchanged from ethanol back to water $\left(3 \times 800 \mathrm{~cm}^{3}\right)$. In order to use the bacterial cellulose in later stages, the neat and modified $\mathrm{BC}$ nanofibres were dispersed in water $\left(500 \mathrm{~cm}^{3}\right)$ and dimethyl carbonate $\left(500 \mathrm{~cm}^{3}\right)$, respectively and subsequently freeze-dried (Edwards Modulyo freeze dryer, West Sussex, UK). The BC nanofibres modified with acetic, hexanoic and dodecanoic acids were termed $\mathrm{C}_{2}-\mathrm{BC}, \mathrm{C}_{6}-\mathrm{BC}$ and $\mathrm{C}_{12}-\mathrm{BC}$, respectively. The scanning electron micrographs of the (modified) $\mathrm{BC}$ nanofibres can be found in the supplementary information.

\subsection{Characterisation of neat and modified BC}

\subsubsection{Attenuated Total Reflection Infrared spectroscopy (ATR-IR)}

ATR-IR spectra were recorded using a Spectrum One FTIR-spectrometer (Perkin Elmer, Massachusetts, USA). The spectra were collected at a resolution of $2 \mathrm{~cm}^{-1}$, in the range of $600 \mathrm{~cm}^{-1}$ and $4000 \mathrm{~cm}^{-1}$. A total of 16 scans were used to obtain each spectrum.

\subsubsection{Preparation of sheets of (modified) bacterial cellulose (paper)}

In order to aid the characterisation of modified BC, paper-like BC sheets made from (modified) BC suspensions were prepared. Initially the (modified) BC water dispersions were centrifuged and the wet centrifuged cake (the sediment) of $\mathrm{BC}$ was placed on a plate, spread with a spatula to a circular wet mass and finally placed into a hot press (George E Moore and Sons, Birmingham, UK) held at $110^{\circ} \mathrm{C}$. Once the moisture from $\mathrm{BC}$ has been evaporated, the dried $\mathrm{BC}$ was then compressed at a pressure of $5 \mathrm{t}$ for $5 \mathrm{~min}$ at the same temperature, to produce a flat $\mathrm{BC}$ sheet. Such sheets made from neat or modified BC suspensions were used for Raman spectroscopy, X-ray diffraction and contact angle measurements.

\subsubsection{Water/air contact angle measurements}

In order to determine the hydrophobicity of modified BC, water/air contact angles were measured on $\mathrm{BC}$ sheets/paper made from (modified) $\mathrm{BC}$ suspensions. Advancing $\theta_{\mathrm{a}}$ and receding $\theta_{\mathrm{r}}$ water/air contact angles on the (modified) $\mathrm{BC}$ sheets were measured using the 
sessile drop method (DSA $10 \mathrm{Mk}$ 2, Krüss GmbH, Hamburg, Germany) at room temperature. Images of the sessile drops were processed using DSA software version 1.80.1.12. At least 5 measurements were taken for each sample.

\subsubsection{Streaming-potential measurements}

The $\zeta$-potentials of neat and modified BC were measured using an eletrokinetic analyser (EKA, Anton Paar, Graz, Austria) based on the streaming potential method. In order to exclude any overlaying effects due to swelling (for BC) or extraction of water-soluble components from the samples, the $\mathrm{pH}$ dependency of $\zeta$-potential was measured only after a time dependent $\zeta$-potential measurement was completed. During the $\zeta=\mathrm{f}(t)$ measurement, the streaming potential was generated by applying a steady pressure increase to 250 mbar across a channel, which was created by stacking the previously mentioned (modified) BC sheets in between a PTFE film The $\mathrm{pH}$ dependency of the $\zeta$ potential was then measured by changing the $\mathrm{pH}$ of the electrolyte solution through the titration of $0.1 \mathrm{~N} \mathrm{HCl}$ or $\mathrm{KOH}$ into $\mathrm{KCl}$ solution, using a titration unit (RTU, Anton Paar, Graz, Austria).

\subsubsection{Determination of the degree of surface substitution of cellulose using Dynamic Vapour Sorption (DVS)}

In order to determine the degree of surface substitution of modified BC by organic acids, a method based on hydrogen/deuterium (H/D) exchange was developed following on from early work reported in literature (Frilette et al. 1948). This measurement was carried out using DVS (DVS-Advantage, Surface Measurement Systems Ltd, Alperton, UK). Approximately $30 \mathrm{mg}$ of freeze dried BC was placed in the sample pan and it was preconditioned at $0 \%$ relative humidity $(\mathrm{RH})$ of deuterium oxide $\left(\mathrm{D}_{2} \mathrm{O}\right)$ for $5 \mathrm{~h}$ at room temperature to remove any adsorbed water molecules. The $\mathrm{RH}$ of $\mathrm{D}_{2} \mathrm{O}$ was increased to $90 \%$ for $2 \mathrm{~h}$ to allow for the adsorption of $\mathrm{D}_{2} \mathrm{O}$ molecules and hence, the H/D exchange with the accessible hydroxyl groups of $\mathrm{BC}$. The $\mathrm{RH}$ was then reduced to $0 \%$ for $2 \mathrm{~h}$ to allow the $\mathrm{D}_{2} \mathrm{O}$ molecules to desorb. This cycle was repeated 10 times such that the H/D exchange can occur on all accessible hydroxyl groups. A short adsorption time of $2 \mathrm{~h}$ was employed to avoid bulk sorption of BC, as only the accessible hydroxyl groups were of 
interest. The sample was then post-conditioned at $0 \% \mathrm{RH}$ for $5 \mathrm{~h}$ to remove any residual adsorbed $\mathrm{D}_{2} \mathrm{O}$ molecules. As the deuterium atom is one neutron heavier than hydrogen, the mass increase after the post-conditioned $\mathrm{BC}$ was measured in situ by an ultrasensitive microbalance (with an accuracy of $\pm 0.05 \mu \mathrm{g}$ ) and the amount of accessible hydroxyl groups available was back calculated from this mass increase:

$$
\Delta m=\frac{O H \times m_{i} \times A \times m_{n}}{162140}
$$

where $\Delta m=$ mass change after hydrogen-deuterium exchange $(\mathrm{mg}), O H=$ accessible hydroxyl groups, $m_{i}=$ initial mass of sample (mg), $A$ = Avogadro's number and $m_{n}=$ mass of a neutron (in $\mathrm{mg}$ ). The number 162140 represents the molecular mass of a single

glucose unit having the unit of $\mathrm{mg} \mathrm{mol}^{-1}\left(\mathrm{C}_{6} \mathrm{H}_{10} \mathrm{O}_{5}\right)$. The derivation of this equation can be found in supplementary information.

\subsubsection{X-ray diffraction (XRD) to determine crystallinity of neat and modified BC}

The XRD pattern of neat and modified BC was characterised on sheet samples using an X-ray diffractometer (PANalytical X'Pert 1, PANalytical Ltd, Cambridge, UK) using a $1.79 \AA$ cobalt X-ray source. Measurements were taken from $2 \theta=10^{\circ}$ to $45^{\circ}$ at a step size of $0.04^{\circ}$. In order to calculate the crystallinity of BC, Segal's method (Segal et al. 1959) was used. This equation is an empirical equation for estimating the degree of crystallinity in cellulose.

$\chi_{\mathrm{c}}=\frac{I_{002}-I_{\text {amorphous }}}{I_{002}} \times 100 \%$

where $I_{002}$ is the intensity of the 002 reflection plane and $I_{\text {amorphous }}$ is the intensity of the amorphous plane. As a comparison, the crystallinity of the (modified) $\mathrm{BC}$ was also calculated based on the area under the XRD spectrum using equation [3]: 
$\chi_{\mathrm{c}}=\frac{A_{c}}{A_{c}+A_{a}} \times 100 \%$

where $A_{c}$ and $A_{a}$ are the total crystalline area and total amorphous area, respectively, between $10^{\circ}$ and $45^{\circ}$. Scherrer's equation (Patterson 1939),

$L_{(002)}=\frac{K \lambda}{\beta \cdot \cos \theta}$

where $\beta$ is the full width at half maximum of the 002 reflection, $\theta$ is the Bragg's angle in degrees and $K=0.91$, was used to determine the crystallite size $\left(L_{(002)}\right)$, and hence, the structural order of 002 reflection.

\subsubsection{Thermal stability of BC: Thermo Gravimetry Analysis (TGA)}

The thermal degradation behaviour of neat and modified $\mathrm{BC}$ in nitrogen was investigated using high resolution modulated TGA (TGA 2950, TA Instruments, Crawley, UK). A sample size of approximately $1 \mathrm{mg}$ was used. The samples were heated from 25 to $550^{\circ} \mathrm{C}$ at a heating rate of $10^{\circ} \mathrm{C} \mathrm{min}^{-1}$.

\section{Results and discussions}

\subsection{ATR-IR Spectra}

Figure 1 shows the ATR-IR spectra of neat $\mathrm{BC}$ and $\mathrm{BC}$ that was modified with organic acids in dispersion. The spectra were normalised against the intensity of the absorption band corresponding to the (C-O-C) link of cellulose (Ilharco et al. 1997), which is located around $1158 \mathrm{~cm}^{-1}$. The appearance of an absorption band characteristic for carbonyl bonds $(\mathrm{C}=\mathrm{O})$ around $1750 \mathrm{~cm}^{-1}$ can be seen. This is a direct result of the introduction of hydrophobic esters onto $\mathrm{BC}$ via the esterification reaction. The hydroxyl group absorption (-OH) around $3300 \mathrm{~cm}^{-1}$ did not seem to decrease significantly with the modification $\left(\mathrm{C}_{2}-\mathrm{BC}\right.$ is the exception). This result suggests that the modification occurred essentially only on the surface of the nanofibres or in the amorphous fraction of the cellulose. Since the modification reaction did not result in dissolution of $\mathrm{BC}$, the 
accessible hydroxyl groups for esterification are essentially only at the surface and in the amorphous regions of the $\mathrm{BC}$. The more intense $1750 \mathrm{~cm}^{-1}$ adsorption band in $\mathrm{C}_{2}-\mathrm{BC}$ is caused by the higher reactivity of acetic acid compared to hexanoic and dodecanoic acid; in analogy to the lipase-catalysed esterification reaction of fatty acids with disaccharides (Pedersen et al. 2002). Therefore, more ethanoate ester bonds form readily on BC. This is also accompanied by increases in the absorption band intensities around $900 \mathrm{~cm}^{-1}, 1280$ $\mathrm{cm}^{-1}$ and $1360 \mathrm{~cm}^{-1}$. These absorption bands correspond to the $-\mathrm{CH}$ vibrations (Ilharco et al. 1997) arising from the methyl groups. $\mathrm{C}_{2}-\mathrm{BC}$ also showed a peak around $1650 \mathrm{~cm}^{-1}$, which can be attributed to the symmetric deformation vibration of adsorbed water molecules (van den Berg et al. 2007). Due to the more hydrophilic nature of $\mathrm{C}_{2}-\mathrm{BC}$ as compared to $\mathrm{C}_{6}-\mathrm{BC}$ and $\mathrm{C}_{12}-\mathrm{BC}$ (see section 3.2), the full elimination of adsorbed water molecules proved to be difficult for acetic acid modified cellulose samples (van den Berg et al. 2007; Radiman and Yulianil 2008).

\subsection{Wettability of bacterial cellulose and modified bacterial cellulose}

In order to obtain qualitative information about the hydrophilicity/hydrophobicity of modified BC nanofibres, the water/air contact angle as measure of the wettability of modified BC was determined using the sessile drop method on paper-like BC sheets made from (modified) $\mathrm{BC}$ nanofibres. It can be seen that both advancing $\theta_{\mathrm{a}}$ and receding $\theta_{\mathrm{r}}$ water contact angles increased with increasing carbon chain length of the organic acid used to modify the $\mathrm{BC}$ nanofibre surface (Table 1). The esterification reaction introduced hydrophobic groups onto the surface of BC. The longer the length of the hydrocarbon chain with which the $\mathrm{BC}$ nanofibres were modified, the more hydrophobic was the BC surface leading to the observed increase in water contact angles on BC sheets. It must be noted however that the contact angles presented here are not equilibrium contact angles of $\mathrm{BC}$ nanofibres, as the roughness of the $\mathrm{BC}$ sheets cannot be easily taken into account. The roughness effect will cause the water droplet(s) to (i) follow the actual microtexture induced by surface roughness (corresponding to the Wenzel state) or (ii) contact only the top asperities, entrapping air below and so create a composite (Cassie-Baxter) wetting state. Both wetting states exaggerate the hydrophilicity and hydrophobicity (Callies and Quere 2005). The difference between these limiting (advancing and receding) contact 
angles is referred to as contact angle hysteresis $\left(\Delta \theta=\theta_{\mathrm{a}}-\theta_{\mathrm{r}}\right)$. This hysteresis can be attributed to surface chemical heterogeneity, roughness or kinetic effects such as swelling or hydrophobic recovery (Olah et al. 2005). The large $\Delta \theta$ observed suggests a Wenzel state. Removing water from such rough surface will make water contact itself (as a result of water leftover in the microtexture), yielding low receding contact angles.

\section{3 $\quad \xi$-potentials of (modified) BC sheets}

Measured $\zeta$-potentials reflect the composition of the electric double layer on a substrate. It is used to approximate the electrostatic potential at the beginning of the diffusive part of the double layer (Hunter 1993). The $\zeta=\mathrm{f}(\mathrm{pH})$ of neat and modified BC (Figure 2) shows that neat and modified $\mathrm{BC}$ possess acidic surface groups (-OH groups) giving rise to a low isoelectric point (iep), where $\xi=0$, and a plateau region in the alkaline $\mathrm{pH}$ range. The plateau observed at high $\mathrm{pH}$ is a result of the full dissociation of acidic functional groups and, therefore, the surface is negatively charged. Lowering the $\mathrm{pH}$ of the electrolyte solution decreased the magnitude of $\zeta$-potential due to the repression of the dissociation of acidic functional groups on the surface of (modified) BC. Ultimately, the $\zeta$-potential changes sign to a positive value as a result of proton $\left(\mathrm{H}_{3} \mathrm{O}^{+}\right)$adsorption. The iep and $\zeta_{\text {plateau }}$ are tabulated in Table 1. Neat BC has an iep at $\mathrm{pH} 3.7$ and a $\zeta_{\text {plateau }}$ of -7.5 $\mathrm{mV}$. This measurement is in agreement with $\zeta$-potentials measured by Blaker et al. (Blaker et al. 2009). A slight shift in iep (although it is within error) and a decrease in $\zeta_{\text {plateau }}$ can be observed for organic acid modified BC. This is not surprising as the modification of $\mathrm{BC}$ with organic acids does affect its surface properties, such as wettability and $\zeta$-potentials. The surface modification of BC does not only increase the hydrophobicity of BC nanofibres but also the $\zeta_{\text {plateau }}$ values. The slight increase of the iep to higher $\mathrm{pH}$ for the modified $\mathrm{BC}$ is due the loss of acidic functional groups as a result of the esterification reaction. The dramatic decrease in $\zeta_{\text {plateau }}$ from $-7.5 \mathrm{mV}$ for neat $\mathrm{BC}$ to $-22.8 \mathrm{mV}$ for the modified $\mathrm{BC}$ could be attributed to the increase in hydrophobicity of the material. Due to the hydrophobic nature of the modified BC surfaces, water molecules could not adsorb as easily onto the surface, which resulted an increase of the 
concentration of electrolyte ions in the electrochemical double layer and, therefore, a smaller $\xi_{\text {plateau }}$ was observed.

\subsection{Degree of surface substitution (DSS) of modified BC or amount of accessible OH groups}

Figure 3 shows a typical example of the dynamic $\mathrm{D}_{2} \mathrm{O}$ vapour sorption on neat $\mathrm{BC}$. The amount of accessible hydroxyl groups and the degree of surface substitution are tabulated in Table 1. No bulk sorption of $\mathrm{D}_{2} \mathrm{O}$ on bacterial cellulose was observed as only one plateau was seen when exposing neat $\mathrm{BC}$ to $\mathrm{D}_{2} \mathrm{O}$ for $48 \mathrm{~h}$ at $90 \% \mathrm{RH}$ (see Figure 4). Our results are also in agreement with results obtained by other researchers (Nishiyama et al. 1999). In order to access the bulk of bacterial cellulose, high temperature annealing of cellulose is required. Goussé et al. (2002) have determined the amount of accessible hydroxyl groups of tunicin whiskers based on geometrical calculations. The authors arrived at a value of 1.5 (out of a maximum of 3 ). In this study, the amount of accessible hydroxyl groups of neat $\mathrm{BC}$ was found to be 1.24. This value is very close to the theoretical predictions of Goussé et al. (2002). The discrepancy can be attributed to the difference in crystal structure between $\mathrm{BC}$ and tunicin whiskers $\left(\mathrm{BC}\right.$ is rich in $\mathrm{I}_{a}$ (Sugiyama et al. 1991), while tunicin whiskers are thought to have a $I_{\beta}$ structure (Belton et al. 1989)). In addition to this, the formation of hydrogen bonds between freeze-dried $\mathrm{BC}$ nanofibres can occur, which will lower the amount of accessible hydroxyl groups.

As the carbon chain length of the organic acid used for the surface modification of BC nanofibres increases and its reactivity decreases, the amount of hydroxyl groups present on the modified surface increases. In addition to this, packing efficiency between $\mathrm{BC}$ nanofibres will also be affected by the esterification. Hydrogen bonds between $\mathrm{BC}$ nanofibres arise from the presence of large amounts of $\mathrm{OH}$ groups on the surface of neat BC. However, the packing efficiency reduces as a result of the grafted long chain hydrocarbon. It is thought that the longer the grafted hydrocarbon chain, the lower the packing efficiency. Therefore, the effective hydrogen bonds between the $\mathrm{BC}$ nanofibres will no doubt decrease

\subsection{XRD of neat and modified BC}


Crystallographically, BC has a cellulose-I structure (Iguchi et al. 2000). Its X-ray diffraction pattern is shown in Figure 5. The peaks shown correspond to the diffraction planes of 101, 101, 002 and 040, respectively (Freire et al. 2006). No peak shifting or appearance of new peaks was observed (Figure 5). This is further evidence to suggest that the surface modification of $\mathrm{BC}$ with organic acids occurred essentially only on the surface of or in the amorphous region of BC. The crystallinity of neat and modified BC as determined using the Segal-equation is tabulated in Table 2. It can be seen that the acetic acid modification led to a slight decrease in the $\mathrm{BC}$ crystallinity. This can be explained by the high reactivity of acetic acid compared to hexanoic and dodecanoic acids (Pedersen et al. 2002). As already mentioned, the high reactivity of acetic acid can lead to more ester bond formation on BC. This result is also in agreement with the ATRIR spectra of $\mathrm{C}_{2}-\mathrm{BC}$, where the intensity of the adsorption band for carbonyl bonds is significantly higher than for $\mathrm{C}_{6}-\mathrm{BC}$ and $\mathrm{C}_{12}-\mathrm{BC}$. As a comparison, the degrees of crystallinity of the (modified) $\mathrm{BC}$ were also calculated based on the crystalline and amorphous areas. Discrepancies of the crystallinity values can be seen between Segal's method and the crystallinity calculated based on the area under the XRD spectra. Similar results were also presented in the literature (Thygesen et al. 2005). The original work by Segal et al. (Segal et al. 1959) was based on cotton cellulose, which is also pure cellulose. This aspect is very similar to bacterial cellulose, which is pure crystalline cellulose without other impurities. Since this current work compares cellulose from the same source (similar to Segal et al. (1959) have conducted), it can be assumed that crystallinity based on Segal's method is preferred and valid for this work.

\subsection{Thermal degradation behaviour of neat and modified BC}

Figure 6 shows the thermal degradation behaviour of neat and modified BC. All the samples underwent single step degradation. It can also be seen that the onset of degradation (defined as temperature at which 10\% mass loss occurred) shifted to lower temperature with increasing carbon chain length of organic acids attached to the surface of BC (Table 3). Similar results were also obtained by Jandura et al. (2000), who modified pulp fibres with oleic and stearic acids. By increasing the carbon chain length, the temperature at which the maximum rate of weight loss (the peak of the derivative 
curves) decreased. This is thought the due to the reduced number of effective hydrogen bonds between $\mathrm{BC}$ nanofibres, as the nanofibres can then not be closely packed. In addition to this, as the amount of hydroxyl groups decreased due to the esterification reaction, the number of potential hydrogen bonds that can be formed decreased too. This results in the reduction of hydrogen bonds formation between nanofibres, which further reduces the thermal stability when compared to neat $\mathrm{BC}$.

\section{Conclusions}

The hydrophilic surface of $\mathrm{BC}$ was rendered hydrophobic via an esterification reaction with organic acids (acetic, hexanoic and dodecanoic acids). It was found that the degree of hydrophobicity of $\mathrm{BC}$ can be tailored by the carbon chain length of the organic acids used to modify BC. The amount of accessible hydroxyl groups on the surface of $\mathrm{BC}$ was determined using a $\mathrm{H} / \mathrm{D}$ exchange method implemented using dynamic vapour sorption of $\mathrm{D}_{2} \mathrm{O}$ and it was found to be 1.24 (out of a maximum of 3 ). In addition to this, the degree of surface hydroxyl group substitution decreases with increasing carbon chain length of the organic acids used. The esterification reaction did not alter the crystallinity of $\mathrm{BC}$ significantly, with $\mathrm{C}_{2}$ - $\mathrm{BC}$ being the exception. The decrease in the crystallinity of $\mathrm{C}_{2}-\mathrm{BC}$ was attributed to the higher reactivity of acetic acid as compared to hexanoic and dodecanoic acid, which led to higher degree of modification. The thermal behaviour of neat and organic acid modified $\mathrm{BC}$ sheets decreased with increasing carbon chain length of the organic acids used. This is evidence of low packing efficiency, arising from the grafted hydrocarbon chains and, therefore, the reduced overall interaction between the nanofibres. As a result of the modification, the hydrophobic BC can easily be dispersed in hydrophobic PLLA and the compatibility (interfacial adhesion) to PLLA could be improved. Therefore, the mechanical properties of the resulting (modified) $\mathrm{BC}$ reinforced PLLA nanocomposites was improved (Lee et al. 2009).

\section{Acknowledgement}

The authors greatly acknowledge the funding provided by the UK Engineering and Physical Science Research Council (EPSRC) for KYL (EP/F032005/1), FQ 
$(\mathrm{EP} / \mathrm{F} 028946 / 1)$ and the Challenging Engineering Programme of the EPSRC $(\mathrm{EP} / \mathrm{E} 007538 / 1)$ for JJB.

\section{References}

Baltazar-y-Jimenez A, Bistritz M, Schulz E, Bismarck A (2008) Atmospheric air pressure plasma treatment of lignocellulosic fibres: Impact on mechanical properties and adhesion to cellulose acetate butyrate. Comp Sci Tech 68 (1):215-227

Baltazar-y-Jimenez A, Juntaro J, Bismarck A (2008a) Effect of Atmospheric Air Pressure Plasma Treatment on the Thermal Behaviour of Natural Fibres and Dynamical Mechanical Properties of Randomly-Oriented Short Fibre Composites. J Biobased Mater Bioenergy 2 (3):264-272

Belton PS, Tanner SF, Cartier N, Chanzy H (1989) High-Resolution Solid-State C-13 Nuclear Magnetic-Resonance Spectroscopy of Tunicin, an Animal Cellulose. Macromolecules 22 (4):1615-1617

Berlioz S, Molina-Boisseau S, Nishiyama Y, Heux L (2009) Gas-Phase Surface Esterification of Cellulose Microfibrils and Whiskers. Biomacromolecules 10 (8):21442151

Bismarck A (2008) Are hierarchical composite structures the way forward to improve the properties of truly green composites? Express Polym Lett 2 (10):687-687

Bismarck A, Mishra S, Lampke T (2005) Plant Fibers as Reinforcement for Green Composites. In: Mohanty AK, Misra M, Drzal LT (eds) Natural Fibers, Biopolymers and Biocomposites. First edn. CRC Press, Boca Raton,

Blaker JJ, Lee KY, Li XX, Menner A, Bismarck A (2009) Renewable nanocomposite polymer foams synthesized from Pickering emulsion templates. Green Chem 11 (9):1321-1326

Callies M, Quere D (2005) On Water Repellency. Soft Matter 1 (1):55-61

Chanliaud E, Burrows KM, Jeronimidis G, Gidley MJ (2002) Mechanical Properties of Primary Plant Cell Wall Analogues. Planta 215 (6):989-996

Cichocki FR, Thomason JL (2002) Thermoelastic anisotropy of a natural fiber. Comp Sci Tech 62 (5):669-678

Czaja W, Romanovicz D, Brown RM (2004) Structural Investigation of Microbial Cellulose Produced in Stationary and Agitated Culture. Cellulose 113-4 (403-411)

Czaja WK, Young DJ, Kawecki M, Brown RM (2007) The Future Prospects of Microbial Cellulose in Biomedical Applications. Biomacromolecules 8 (1):1-12

Eichhorn SJ, Davies GR (2006) Modelling the crystalline deformation of native and regenerated cellulose. Cellulose 13 (3):291-307

Eichhorn SJ, Dufresne A, Aranguren M, Marcovich NE, Capadona JR, Rowan SJ, Weder C, Thielemans W, Roman M, Renneckar S, Gindl W, Veigel S, Keckes J, Yano H, Abe K, Nogi M, Nakagaito AN, Mangalam A, Simonsen J, Benight AS, Bismarck A, Berglund LA, Peijs T (2010) Review: current international research into cellulose nanofibres and nanocomposites. J Mater Sci 45 (1):1-33 
Freire CSR, Silvestre AJD, Neto CP, Belgacem MN, Gandini A (2006) Controlled heterogeneous modification of cellulose fibers with fatty acids: Effect of reaction conditions on the extent of esterification and fiber properties. J Appl Polym Sci 100 (2): 1093-1102

Frilette VJ, Hanle J, Mark H (1948) Rate of exchange of cellulose with heavy water. J Amer Chem Soc 70 (3):1107 - 1113

Gardner DJ, Oporto GS, Mills R, Samir MASA (2008) Adhesion and Surface Issues in Cellulose and Nanocellulose. J Adhesion Sci Technol 22 (5-6):545-567

Gindl W, Keckes J (2004) Tensile Properties of Cellulose Acetate Butyrate Composites Reinforced with Bacterial Cellulose. Comp Sci Tech 64 (15):2407-2413

Gousse C, Chanzy H, Excoffier G, Soubeyrand L, Fleury E (2002) Stable suspensions of partially silylated cellulose whiskers dispersed in organic solvents. Polymer 43 (9):26452651

Hsieh YC, Yano H, Nogi M, Eichhorn SJ (2008) An Estimation of the Young's Modulus of Bacterial Cellulose Filaments. Cellulose 15 (4):507-513

Hunter RJ (1993) Introduction to modern colloid science. Oxford University Press Inc. , New York

Ifuku S, Nogi M, Kentaro A, Keishin H, Nakatsubo F, Yano H (2007) Surface Modification of Bacterial Cellulose Nanofibers for Property enhancement of Optical Transparent Composites: Dependence on Acetyl-Group DS. Biomacromolecules 8 (6):1937-1978

Iguchi M, Yamanaka S, Budhiono A (2000) Bacterial Cellulose - a Masterpiece of Nature's Arts. J Mater Sci 35 (2):261-270

Ilharco LM, Gracia RR, daSilva JL, Ferreira LFV (1997) Infrared Approach to the Study of Adsorption on Cellulose: Influence of Cellulose Crystallinity on the Adsorption of Benzophenone. Langmuir 13 (15):4126-4132

Jandura P, Riedl B, Kokta BV (2000) Thermal degradation behavior of cellulose fibers partially esterified with some long chain organic acids. Polym Degrad Stabil 70 (3):387394

Juntaro J (2009) Environmentally friendly hierarchical composites. PhD Thesis, Imperial College London, London

Juntaro J, Pommet M, Kalinka G, Mantalaris A, Shaffer MSP, Bismarck A (2008) Creating hierarchical structures in renewable composites by attaching bacterial cellulose onto sisal fibers. Adv Mater 20 (16):3122-3126

Juntaro J, Pommet M, Mantalaris A, Shaffer M, Bismarck A (2007) Nanocellulose enhanced interfaces in truly green unidirectional fibre reinforced composites. Compos Interfaces 14 (7-9):753-762

Klemm D, Heublein B, Fink HP, Bohn A (2005) Cellulose: Fascinating Biopolymer and Sustainable Raw Material. Angew Chem - Intern Ed 44 (22):3358-3393

Lee K-Y, Blaker JJ, Bismarck A (2009) Surface Functionalisation of Bacterial Cellulose as the Route to Produce Green Polylactide Nanocomposites with Improved Properties. Comp Sci Tech 69 (15-16):2724 - 2733 
Li X, Tabil LG, Panigrahi S (2007) Chemical treatments of natural fiber for use in natural fiber-reinforced composites: A review. J Polym Environ 15 (1):25-33

Mathew AP, Oksman K, Sain M (2005) The Effect of Morphology and Chemical Characteristics of Cellulose Reinforcements on the Crystallinity of Polylactic Acid. J Appl Polym Sci 101 (1):300-310

Nakagaito AN, Fujimura A, Sakai T, Hama Y, Yano H (2009) Production of Microfibrillated Cellulose (MFC)-Reinforcced Polylactic Acid (PLA) Nanocomposites from Sheets obtained by a Papermaking-like Process. Comp Sci Techn 69 (7-8):12931297

Nishi Y, Uryu M, Yamanaka S, Watanabe K, Kitamura N, Iguchi M, Mitsuhashi S (1990) The Structure and Mechanical Properties of Sheets Prepared from Bacterial Cellulose. 2. Improvement of the Mechancial Properties of Sheets and Their Applicability to Diaphragms of Electroacoustic Transducers. J Mater Sci 25 (6):2997-3001

Nishino T, Matsuda I, Hirao K (2004) All-cellulose composites. Macromolecules 37 (20):7683-7687

Nishiyama Y, Isogai A, Okano T, Muller M, Chanzy H (1999) Intracrystalline deuteration of native cellulase. Macromolecules 32 (6):2078-2081

Nogi M, Abe K, Handa K, Nakatsubo F, Ifuku S, Yano H (2006) Property Enhancement of Optical Transparent Bionanofiber Composites by Acetylation. Appl Phys Lett 89 (23):233123

Olah A, Hillborg H, Vancso GJ (2005) Hydrophobic recovery of UV/ozone treated poly(dimethylsiloxane): adhesion studies by contact mechanics and mechanism of surface modification. Appl Surf Sci 239 (3-4):410-423

Patterson AL (1939) The Scherrer Formula for X-Ray Particle Size Determination. Phys Rev 56 (10):978

Pedersen NR, Wimmer R, Emmersen J, Degn P, Pedersen LH (2002) Effect of fatty acid chain length on initial reaction rates and regioselectivity of lipase-catalysed esterification of disaccharides. Carbohydr Res 337 (13):1179-1184

Pommet M, Juntaro J, Heng JYY, Mantalaris A, Lee AF, Wilson K, Kalinka G, Shaffer MSP, Bismarck A (2008) Surface modification of natural fibers using bacteria: Depositing bacterial cellulose onto natural fibers to create hierarchical fiber reinforced nanocomposites. Biomacromolecules 9 (6):1643-1651

Radiman C, Yulianil G (2008) Coconut water as a potential resource for cellulose acetate membrane preparation. Polym Int 57 (3):502-508

Reiling S, Brickmann J (1995) Theoretical Investigations on the Structure and PhysicalProperties of Cellulose. Macromol Theory Simul 4 (4):725-743

Roy D, Semsarilar M, Guthrie JT, Perrier S (2009) Cellulose modification by polymer grafting: a review. Chem Soc Rev 38 (7):2046-2064

Samir M, Alloin F, Dufresne A (2005) Review of recent research into cellulosic whiskers, their properties and their application in nanocomposite field. Biomacromolecules 6 (2):612-626 
Schlufter K, Schmauder HP, Dorn S, Heinze T (2006) Efficient homogeneous chemical modification of bacterial cellulose in the ionic liquid 1-N-butyl-3-methylimidazolium chloride. Macromol Rapid Commun 27 (19):1670-1676

Sczostak A (2009) Cotton Linters: An Alternative Cellulosic Raw Material. Macromol Symp 280:45-53

Segal L, Creely JJ, Martin-Jr AE, Conrad CM (1959) An Emperical Method for Estimating the Degree of Crystallinity of Native Cellulose Using the X-Ray DIffractometer. Text Res J 29 (10):786-794

Suetsugu M, Kotera M, Nishino T Cellulosic Nanocomposite Prepared by Acetylation of Bacterial Cellulose Using Supercritical Carbon Dioxide. In: Conference Proceedings of the $17^{\text {th }}$ International Conference of Composite Materials, Edinburgh, 2009.

Sugiyama J, Vuong R, Chanzy H (1991) Electron-Diffraction Study on the 2 Crystalline Phases Occurring in Native Cellulose from an Algal Cell-Wall. Macromolecules 24 (14):4168-4175

Suryanegara L, Nakagaito AN, Yano H (2009) The Effect of Crystallization of PLA on the Thermal and Mechanical Properties of Microfibrillated Cellulose-Reinforced PLA Composites. Comp Sci Tech 69 (7-8):1187-1192

Thomason JL Why are natural fibres failing to deliver on composite performance? In: Conference Proceedings of the $17^{\text {th }}$ International Conference of Composite Materials, Edinburgh, 2009.

Thygesen A, Oddershede J, Lilholt H, Thomsen AB, Stahl K (2005) On the determination of crystallinity and cellulose content in plant fibres. Cellulose 12 (6):563576

Toyosaki H, Naritomi T, Seto A, Matsuoka M, Tsuchida T, Yoshinaga F (1996) Screening of Bacterial Cellulose-Producing Acetobacter Strains Suitable for Agitated Culture. Biosci Biotech Biochem 59 (8):1498-1502

van den Berg O, Capadona JR, Weder C (2007) Preparation of homogeneous dispersions of tunicate cellulose whiskers in organic solvents. Biomacromolecules 8 (4):1353-1357 


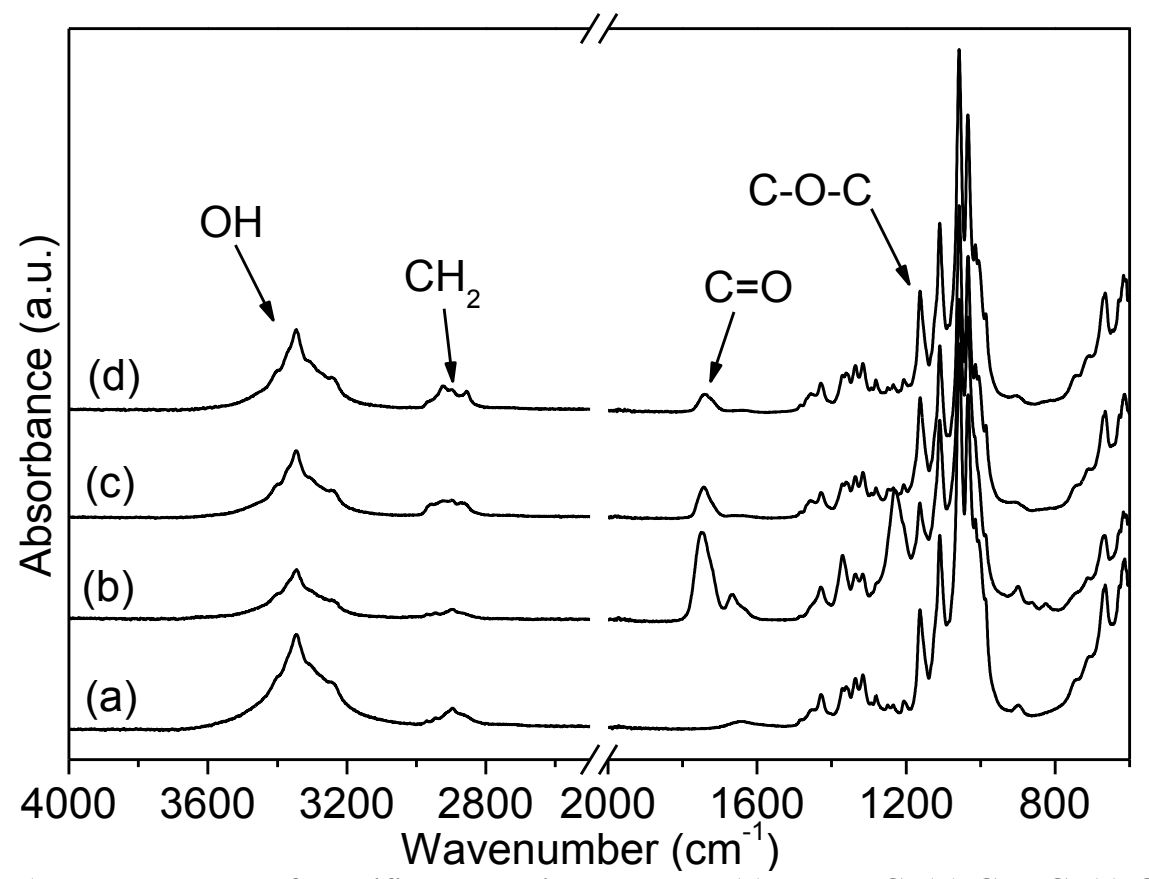

Figure 1. ATR-IR spectra of modified bacterial cellulose. (a) Neat BC, (b) $\mathrm{C}_{2}-\mathrm{BC}$, (c) $\mathrm{C}_{6}-\mathrm{BC}$, (d) $\mathrm{C}_{12^{-}}$ BC.

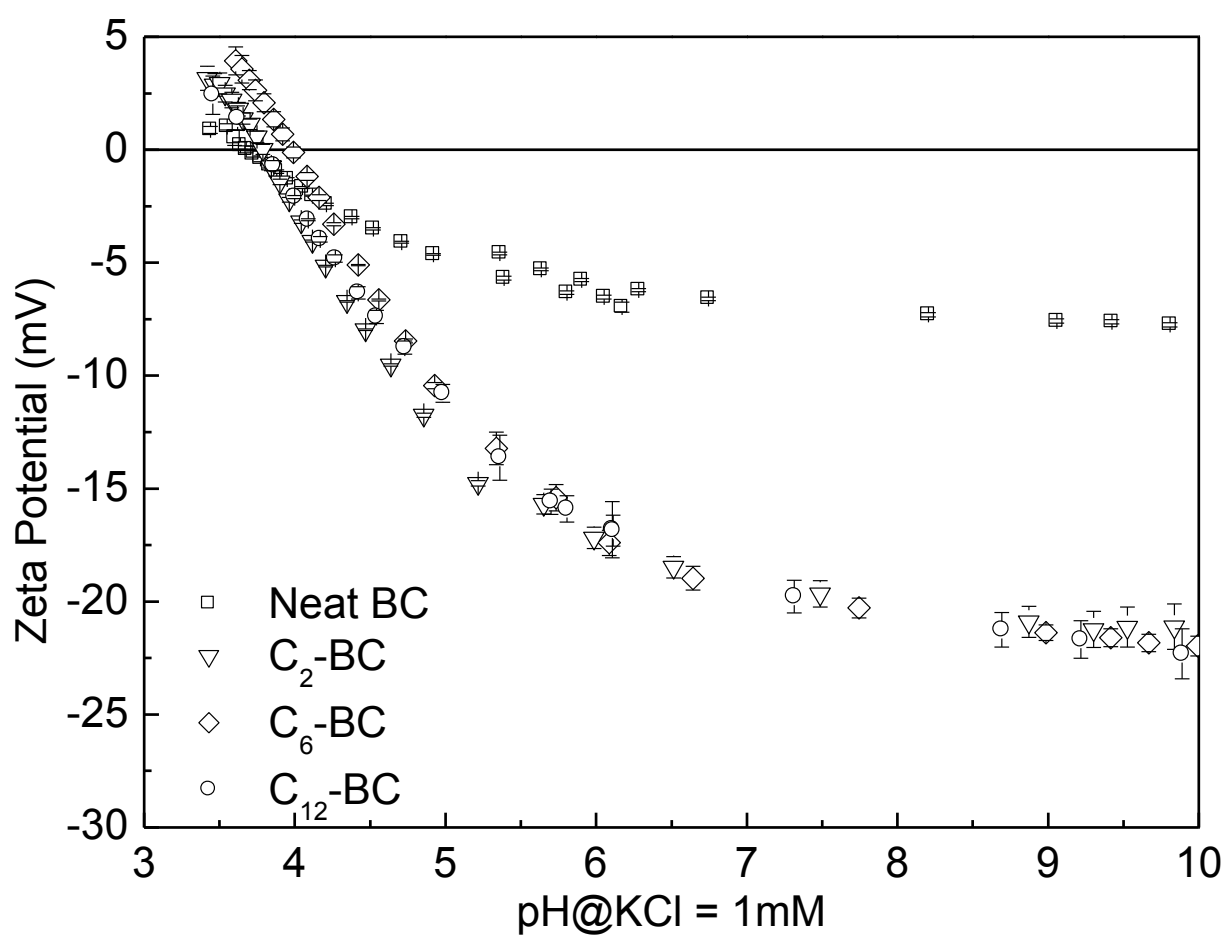

Figure 2: $\zeta$-potentials of neat and modified $\mathrm{BC}$ sheets as function of $\mathrm{pH}$ measured in $1 \mathrm{mM} \mathrm{KCl}$ supporting electrolyte. 


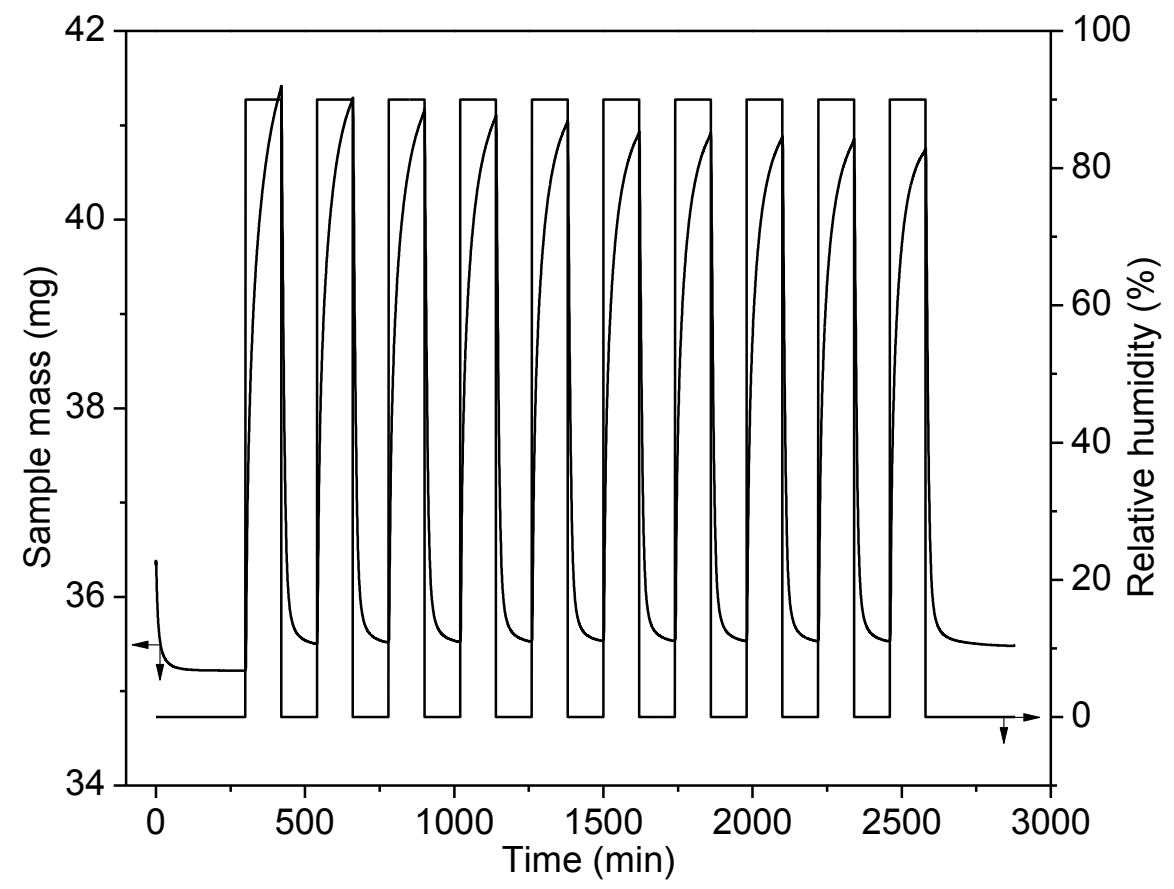

Figure 3. An example of $\mathrm{D}_{2} \mathrm{O}$ adsorption on neat $\mathrm{BC}$.

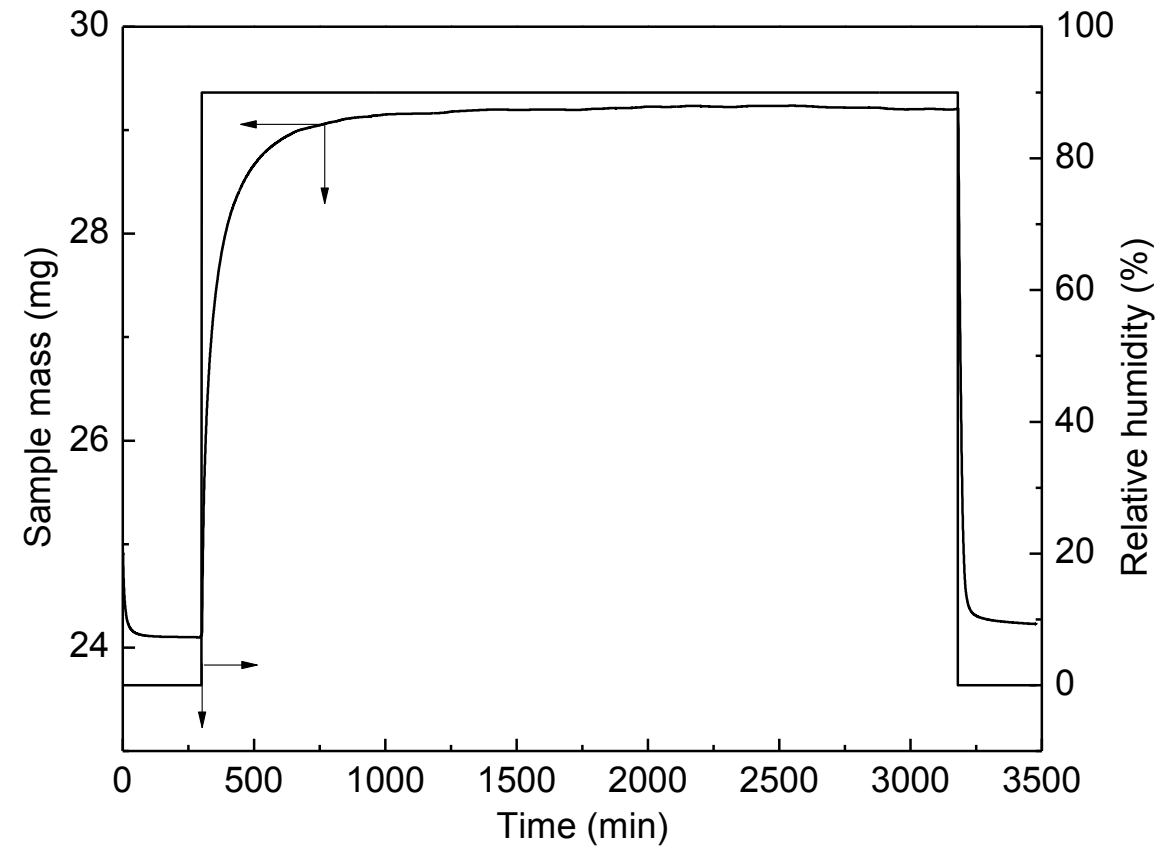

Figure 4. DVS of neat $\mathrm{BC}$ exposed to $\mathrm{D}_{2} \mathrm{O}$ for $48 \mathrm{~h}$ at $90 \%$ relative $\mathrm{D}_{2} \mathrm{O}$ humidity 


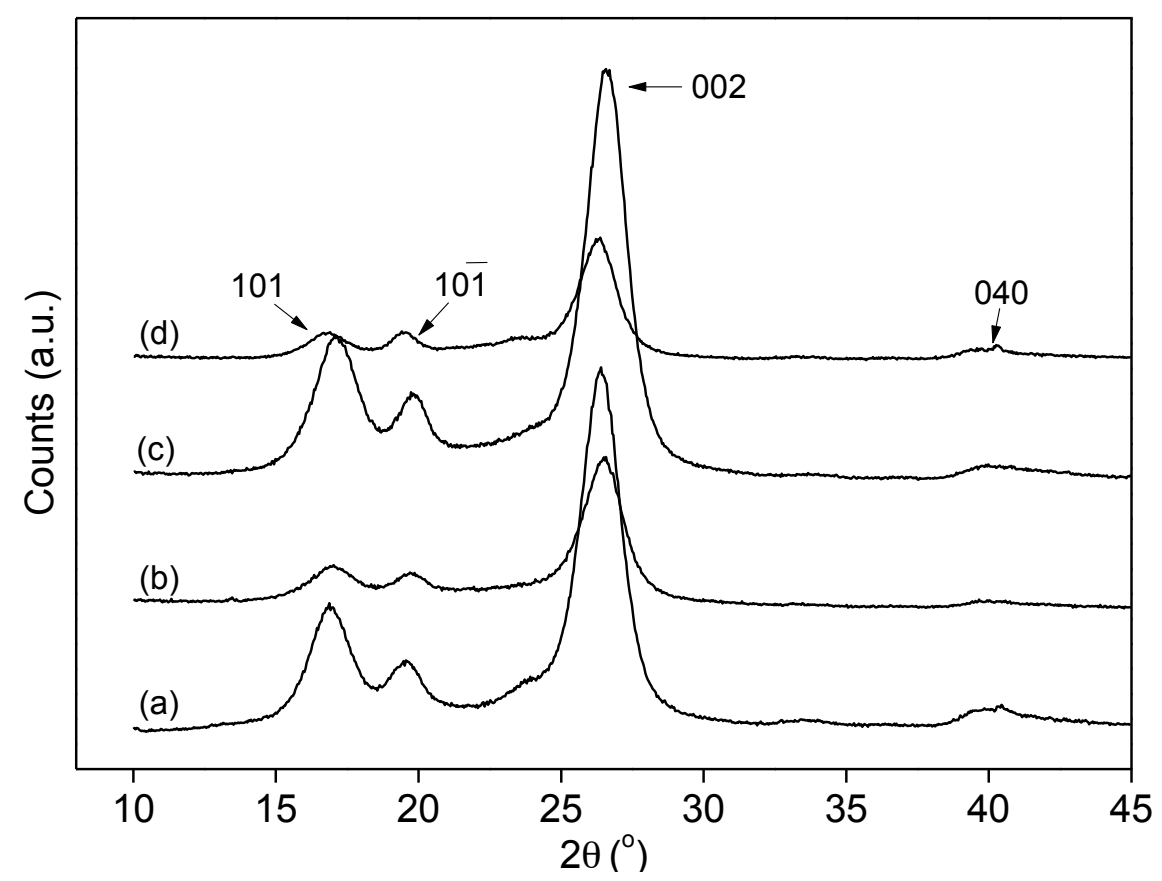

Figure 5. X-ray diffraction pattern of (a) Neat $\mathrm{BC}$, (b) $\mathrm{C}_{2}-\mathrm{BC}$, (c) $\mathrm{C}_{6}-\mathrm{BC}$, (d) $\mathrm{C}_{12}-\mathrm{BC}$ with the 101 , $10 \overline{1}, 002$ and 040 reflections identified.

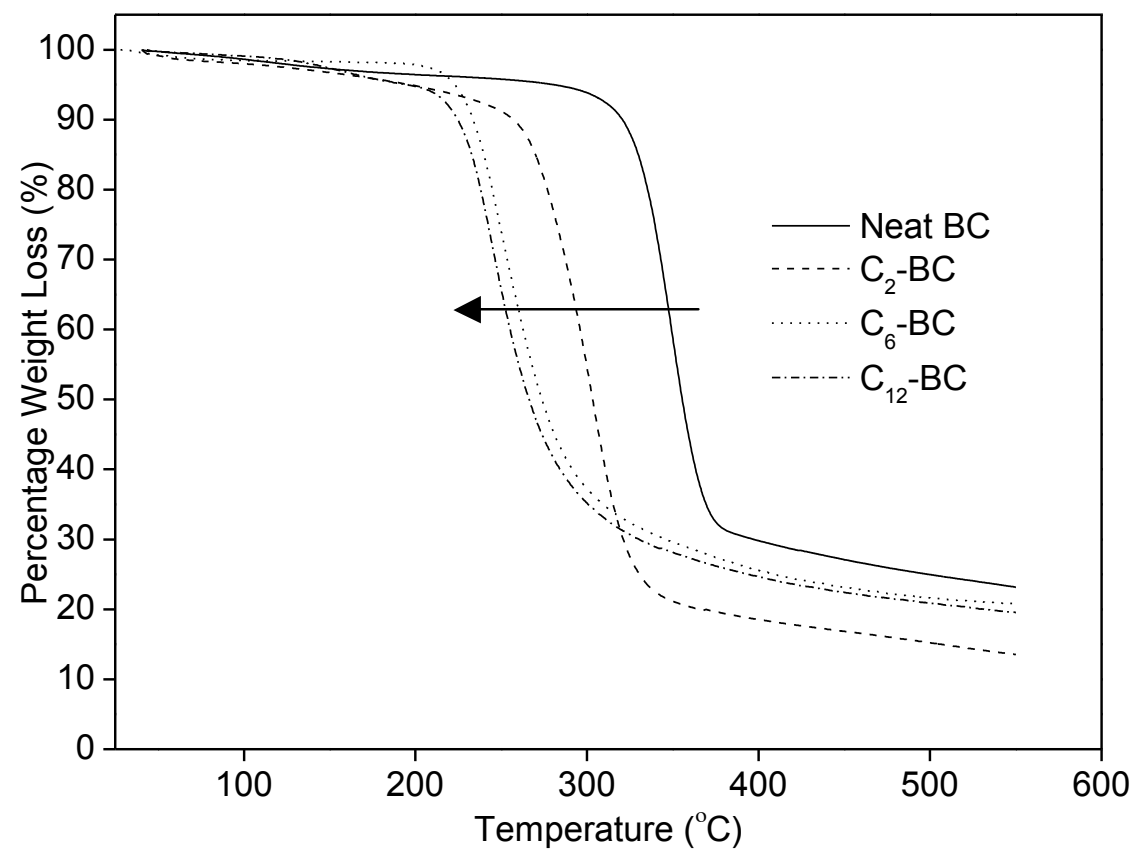

Figure 6. Percentage weight loss as a function of temperature for neat and modified BC. 
Table 1. Advancing $\theta_{\mathrm{a}}$ and receding $\theta_{\mathrm{r}}$ water/air contact angles, contact angle hysteresis $(\Delta \theta)$, isoelectric point (iep), $\zeta$-potential plateau value $\left(\zeta_{\text {plateau }}\right)$, hydroxyl group availability (-OH) and the degree of surface substitution (DSS) of neat and modified BC

\begin{tabular}{cccccccc}
\hline Sample & $\boldsymbol{\theta}_{\mathbf{a}}\left(^{\circ}\right)$ & $\boldsymbol{\theta}_{\mathbf{r}}\left({ }^{\circ}\right)$ & $\boldsymbol{\Delta} \boldsymbol{\theta}\left({ }^{\circ}\right)$ & iep $(\mathbf{p H})$ & $\boldsymbol{\zeta}_{\text {plateau }}(\mathbf{m V})$ & $\mathbf{- O H}^{*}{ }^{\dagger}$ & DSS (\%) \\
\hline Neat BC & $19 \pm 3$ & $12 \pm 2$ & 7 & $3.7 \pm 0.1$ & $-7.5 \pm 0.2$ & 1.24 & 0 \\
$\mathrm{C}_{2}$-BC & $75 \pm 1$ & $35 \pm 2$ & 40 & $3.8 \pm 0.1$ & $-21.1 \pm 0.1$ & 0.01 & 98.9 \\
$\mathrm{C}_{6}$-BC & $92 \pm 1$ & $45 \pm 1$ & 47 & $3.9 \pm 0.1$ & $-21.7 \pm 0.3$ & 0.52 & 58.5 \\
$\mathrm{C}_{12}-\mathrm{BC}$ & $133 \pm 4$ & $80 \pm 4$ & 53 & $3.8 \pm 0.2$ & $-21.8 \pm 0.5$ & 0.60 & 51.9 \\
\hline
\end{tabular}

The $-\mathrm{OH}$ groups availability has a maximum value of 3 as there are $3-\mathrm{OH}$ groups per glucopyranose unit in cellulose.

${ }^{\dagger}$ Due to the sensitivity of the ultra microbalance used in DVS, the error arising from the measurement was statistically insignificant between samples.

Table 2. Degree of crystallinity $\left(\chi_{c}\right)$, full width at half maximum (FWHM) of the 002 diffraction peak at $2 \theta=22.5^{\circ}$, crystallite size of 002 reflection $\left(L_{(002)}\right)$ and the calculated interlayer distance $\left(d_{(002)}\right)$ for neat and modified $B C$.

\begin{tabular}{|c|c|c|c|c|c|}
\hline Sample & $\chi_{\mathrm{c}}(\%)^{\S}$ & FWHM $\left(^{\circ}\right)$ & $\mathbf{L}_{(002)}(\AA)$ & $d_{(002)}(\AA)$ & $\chi_{c}(\%)^{\&}$ \\
\hline Neat BC & $90.2 \pm 0.2$ & $1.71 \pm 0.02$ & $60.81 \pm 0.54$ & $7.85 \pm 0.01$ & $74.4 \pm 0.2$ \\
\hline $\mathrm{C}_{2}-\mathrm{BC}$ & $83.2 \pm 0.2$ & $1.73 \pm 0.01$ & $60.40 \pm 0.39$ & $7.81 \pm 0.01$ & $59.6 \pm 0.8$ \\
\hline $\mathrm{C}_{6}-\mathrm{BC}$ & $89.7 \pm 0.5$ & $1.70 \pm 0.02$ & $61.26 \pm 0.52$ & $7.79 \pm 0.02$ & $70.6 \pm 2.4$ \\
\hline $\mathrm{C}_{12}-\mathrm{BC}$ & $85.1 \pm 0.9$ & $1.60 \pm 0.01$ & $64.93 \pm 0.24$ & $7.87 \pm 0.01$ & $69.3 \pm 5.7$ \\
\hline
\end{tabular}

§ Crystallinity calculated based on Segal’s method.

\& Crystallinity calculated based on integrated area of XRD spectrum.

Table 3. The onset degradation temperature of neat and modified BC.

\begin{tabular}{cc}
\hline Samples & Onset degradation temperature $\left({ }^{\circ} \mathbf{C}\right)$ \\
\hline Neat BC & 319 \\
$\mathrm{C}_{2}-\mathrm{BC}$ & 259 \\
$\mathrm{C}_{6}-\mathrm{BC}$ & 233 \\
$\mathrm{C}_{12}-\mathrm{BC}$ & 225 \\
\hline
\end{tabular}

